\title{
Commentary Pandemic influenza: are we prepared to face our obligations?
} Boris P Ehrenstein

\author{
Department of Internal Medicine (I), University Hospital, Regensburg, Germany
}

Corresponding author: Boris P Ehrenstein, boris.ehrenstein@klinik.uni-r.de

Published: 15 July 2008

Critical Care 2008, 12:165 (doi:10.1186/cc6938)

This article is online at http://ccforum.com/content/12/4/165

(C) 2008 BioMed Central Ltd

See related review by Anantham et al., http://ccforum.com/content/12/3/217

\begin{abstract}
After decades of low personal risk for contracting lethal diseases, physicians are suddenly facing the possibility of a substantial increase in occupational risk during an influenza pandemic. If they are not confronted before the onset of an influenza pandemic, feelings of unease and fear or ignorance about physicians' professional obligations could profoundly hinder individual physicians in fulfilling their professional duties. Such feelings could therefore undermine institutional and societal preparations. In their review published in Critical Care, Anantham and coworkers outline the ethical framework that forms the basis of the professional obligations of physicians who respond to health care emergencies, such as an influenza pandemic.
\end{abstract}

In their review recently published in Critical Care, Anantham and coworkers outline the ethical framework that forms the basis of the professional obligations of physicians who respond to health care emergencies, such as an influenza pandemic [1].

Bearing in mind the high mortality rates reported for the sporadic human cases of $\mathrm{H} 5 \mathrm{~N} 1$ avian influenza and experiences gained confronting the recent SARS (severe acute respiratory syndrome) epidemic, many health care professionals will wonder whether we are well prepared to cope with the anticipated influenza pandemic [2,3]. Worldwide, health authorities and many individual institutions have undertaken substantial efforts to plan and prepare for such a catastrophic event. Confronted with the predicted magnitude of a pandemic in reports presented by the mass or professional media, most physicians might feel at least some unease, if not outright fear, about the duties and associated risks they will have to face in the event of an influenza pandemic. After decades of low personal risk for contracting lethal diseases while providing care to patients, physicians at least in developed countries - are suddenly facing the possibility that occupational risk will increase substantially. If they are not confronted before the onset of an influenza pandemic, these feelings of unease and fear could profoundly hinder individual physicians in fulfilling their professional duties; they could therefore undermine institutional and societal preparations [4-8]. Hence, a reappraisal of the ethical basis of our professional duties as physicians and of justifiable or nonjustifiable limits to these duties should be an integral part of pandemic preparedness efforts, not only for professional organizations and health authorities, but also for individual physicians.

In their review, Anantham and coworkers [1] provide explanations of the basic principles of 'the rule of rescue', the 'free choice of the profession' and the implicit 'contract of the medical profession with society', which help us to understand the inevitability of accepting professional risk as a physician. More important than the discussion of these basic principles are the authors' comments on nonlegitimate and legitimate limits to professional risk. Sheer heroism will not solve the problems that will be encountered during a pandemic, because high-risk behaviours (for example, failure to use universal precautions) might further aggravate problems by rapidly diminishing the numbers of available physicians. Although society has the right to demand service from physicians during a health care crisis, physicians have the reciprocal right to demand sufficient institutional support (for example, protective equipment, chemoprophylaxis and, if available, vaccination) [1,9]. In addition to these logistical provisions, society and institutions will also have to address broader issues, including plans for child and elder care, transportation to work or lodging, and provision of adequate compensation to families of physicians succumbing to disease. Addressing these and other related issues in advance will help institutions to ensure adequate turnout of the medical workforce in the event of a pandemic $[5,9]$.

Although Anantham and coworkers provide a good overview of the ethical issues that arise while preparing for an influenza pandemic, they do not give a detailed 'recipe' for institutions or physicians planning to embark on or to intensify their efforts for pandemic preparedness. National guidelines and reviews are available for many of the logistical and organizational 
issues that health care systems and individual institutions must address [10-13]. However, the evidence suggests that we cannot assume that health care workers will universally accept the increase in occupational risk associated with fulfilling their professional duties during an influenza pandemic $[4,5]$. More research into and reports of successful interventions to improve the acceptance of increased professional risk among health care workers are needed.

Because we - physicians in the fields of emergency medicine, pulmonology, intensive care and infectious diseases - will be among the first to confront a pandemic, the article by Anantham and coworkers should remind us of our professional obligations and enhance our willingness to fulfill those despite associated risks. Otherwise, as the authors concluded, 'influenza will run it's course ... leaving entire populations ravaged and the history will judge (us) harshly.'

\section{Competing interests}

The author declares that he has no competing interests.

\section{References}

1. Anantham D, McHugh W, O'Neill S, Forrow L: Clinical review: Influenza pandemic - physicians and their obligations. Crit Care 2008, 12:217.

2. Abdel-Ghafar AN, Chotpitayasunondh T, Gao Z, Hayden FG, Nguyen DH, de Jong MD, Naghdaliyev A, Peiris JS, Shindo N, Soeroso S, Uyeki TM: Update on avian influenza A (H5N1) virus infection in humans. N Engl J Med 2008, 358:261-273.

3. Wenzel RP, Edmond MB: Managing SARS amidst uncertainty. N Engl J Med 2003, 348:1947-1948.

4. Ehrenstein BP, Hanses F, Salzberger B: Influenza pandemic and professional duty: family or patients first? A survey of hospital employees. BMC Public Health 2006, 6:311.

5. Imai T, Takahashi K, Todoroki M, Kunishima H, Hoshuyama T, Ide R, Kawasaki T, Koyama N, Endo K, Fujita H, Iwata K, Koh G, Chia $\mathrm{SE}$, Koh D: Perception in relation to a potential influenza pandemic among healthcare workers in Japan: implications for preparedness. J Occup Health 2008, 50:13-23.

6. Qureshi K, Gershon RR, Sherman MF, Straub T, Gebbie E, McCollum M, Erwin MJ, Morse SS: Health care workers' ability and willingness to report to duty during catastrophic disasters. $J$ Urban Health 2005, 82:378-388.

7. Straus SE, Wilson K, Rambaldini G, Rath D, Lin Y, Gold WL, Kapral MK: Severe acute respiratory syndrome and its impact on professionalism: qualitative study of physicians' behaviour during an emerging healthcare crisis. BMJ 2004, 329:83.

8. Sokol DK: Virulent epidemics and scope of healthcare workers' duty of care. Emerg Infect Dis 2006, 12:1238-1241.

9. World Health Organization: Ethical considerations in developing a public health response to pandemic influenza [http://www.who.int/csr/resources/publications/ WHO CDS EPR GIP 2007 2c.pdf]

10. Challen K, Bentley A, Bright J, Walter D: Clinical review: mass casualty triage: pandemic influenza and critical care. Crit Care 2007, 11:212.

11. US Department of Health \& Human Services: Pandemic influenza plan [http://www.hhs.gov/pandemicflu/plan/]

12. Nationaler Pandemieplan [in German] [http://www.rki.de/ cln_049/nn_200132/DE/Content/InfAZ/I/Influenza/ influenzapandemieplan_l,templateld=raw,property= publicationFile.pdf/influenzapandemieplan_I.pdf]

13. Clinical management of human infection with avian influenza A (H5N1) virus (updated advice 15 August 2007) [http://www. who.int/csr/disease/avian_influenza/guidelines/ ClinicalManagement07.pdf] 